\title{
Effect of pH Value on Stress Corrosion Cracking of X70 Pipeline Steel in Acidic Soil Environment
}

\author{
Zhiyong $L I U^{1,3)}$, Cuiwei $D U^{1)}$, Xin $Z H A N G^{2)}$, Fuming $W A N G^{2)}$ and Xiaogang $L I^{1) \dagger}$ \\ 1) Corrosion and Protection Center, University of Science and Technology Beijing, Beijing 100083, China \\ 2) Nuclear and Radiation Safety Center, Ministry of Environmental Protection of China, Beijing 100082, China \\ 3) School of Metallurgical and Ecological Engineering, University of Science and Technology Beijing, Beijing 100083, \\ China \\ [Manuscript received 14 November 2012, in revised form 2 April 2013] \\ (C) The Chinese Society for Metals and Springer-Verlag Berlin Heidelberg
}

\begin{abstract}
The effect of $\mathrm{pH}$ value on the stress corrosion cracking (SCC) of API X70 pipeline steel in simulated acidic soil solutions was investigated by using slow strain rate test, electrochemical polarization curves, electrochemical impedance spectroscopy, and scanning electron microscopy. $\mathrm{pH}$ plays an important role in the susceptibility and electrochemical mechanism of SCC. The $\mathrm{pH}$ higher than 5 has no significant effect on electrochemical processes. By contrast, the $\mathrm{pH}$ lower than 5 intensifies cathodic hydrogen evolution reactions, thus increasing the cathodic current and corrosion potential. Under different $\mathrm{pH}$ values, the SCC mechanism of $\mathrm{X} 70$ pipeline steel varies among anodic dissolution ( $A D)$, hydrogen embrittlement $(\mathrm{HE})$, and the combination of $A D$ and $\mathrm{HE}(\mathrm{AD}+\mathrm{HE})$ with variations of applied potential. At $-850 \mathrm{mV}_{\mathrm{SCE}}$, the $\mathrm{SCC}$ mechanism is $\mathrm{HE}$ if $\mathrm{pH}$ is less than 4 or $\mathrm{AD}+\mathrm{HE}$ if $\mathrm{pH}$ value is more positive.
\end{abstract}

KEY WORDS: X70 pipeline steel; Soil environment; pH; Stress corrosion cracking

\section{Introduction}

The construction of high-strength steel pipes has been increasing in China, thus arousing unprecedented concern on pipeline security against corrosion damage in soil environments. According to international investigations, stress corrosion cracking (SCC) is one of the most destructive deteriorations of oil or gas pipelines. Two types of SCC are recognized in soil environments: high-pH (pH of approximately 9) SCC and low-pH SCC, including near-neutral-pH and acidic-pH SCC ${ }^{[1-7]}$. The mechanism of high-pH SCC is anodic dissolution (AD) for passive films at the crack tip between grain boundaries ${ }^{[8]}$. However, no widely acceptable mechanism of low-pH SCC exists. Although considerable research has focused on the detailed mechanism of SCC in near-neutral-pH soil environments, few efforts have been made to investigate the same mechanism in acidic solutions. Parkins

† Corresponding author. Prof., Ph.D.; Tel.: +86 10 62333931; Fax: +86 10 62334005; E-mail address: lixiaogang99@263.net (Xiaogang LI) et al. ${ }^{[3]}$ regarded the mechanism of near-neutral-pH $\mathrm{SCC}$ as the cooperation of $\mathrm{AD}$ and the ingress of hydrogen in steel. Park et al. ${ }^{[9]}$ indicated that SCC in a near-neutral-pH bicarbonate solution initiates a pitto-stress corrosion crack transition mode. On the contrary, Chen et al. ${ }^{[10]}$ recognized that near-neutral-pH SCC follows a dissolution mechanism in the crack initiation and initial growth stages and that hydrogen facilitates the dissolution rate of steel, thus leading to high SCC susceptibility. Beavers et al. ${ }^{[11]}$ revealed that SCC occurs because of AD and is propagated by hydrogen-induced cracking. Wang et al. ${ }^{[12]}$ indicated that SCC is controlled by hydrogen embrittlement (HE) below $-800 \mathrm{mV}_{\mathrm{SCE}}$ and by $\mathrm{AD}$ between -700 and $-500 \mathrm{mV}_{\mathrm{SCE}}$. In acidic soil solutions, hydrogen evolution reactions are intensively promoted owing to the low $\mathrm{pH}$, which increases the SCC susceptibility of pipeline steels. Liu et al..$^{[6,7,13-16]}$ investigated the SCC of pipeline steels in acidic soil environments and concluded that the property of SCC is similar to that of near-neutral-pH environments. However, higher SCC susceptibility causes the SCC mechanism to vary within different potential ranges 
Table 1 Chemical composition of the X70 pipeline steel (wt.\%)

\begin{tabular}{ccccccccccccc}
\hline $\mathrm{C}$ & $\mathrm{Si}$ & $\mathrm{Mn}$ & $\mathrm{Nb}$ & $\mathrm{Ni}$ & $\mathrm{Cr}$ & $\mathrm{Cu}$ & $\mathrm{Al}$ & $\mathrm{Ti}$ & $\mathrm{V}$ & $\mathrm{S}$ & $\mathrm{P}$ & $\mathrm{Fe}$ \\
\hline 0.073 & 0.22 & 1.52 & 0.054 & 0.18 & 0.17 & 0.20 & 0.029 & 0.017 & 0.026 & 0.0022 & 0.0035 & Balance \\
\hline
\end{tabular}

Table 2 Mechanical data of the X70 pipeline steel

\begin{tabular}{cccc}
\hline Yield strength $\sigma_{0.5}(\mathrm{MPa})$ & Ultimate tensile strength $(\mathrm{MPa})$ & Elongation $\delta_{0}(\%)$ & Reduction-in-area $\psi_{0}(\%)$ \\
\hline 565 & 739 & 15.5 & 58.4 \\
\hline
\end{tabular}

Note: Measured according to standard GB/T 228.1-2010

Table 3 Chemical composition of the test solution $\left(\mathrm{g} \cdot \mathrm{L}^{-1}\right)$

\begin{tabular}{cccccc}
\hline $\mathrm{CaCl}_{2}$ & $\mathrm{NaCl}$ & $\mathrm{Na}_{2} \mathrm{SO}_{4}$ & $\mathrm{MgSO}_{4} \cdot 7 \mathrm{H}_{2} \mathrm{O}$ & $\mathrm{KNO}_{3}$ & $\mathrm{NaHCO}_{3}$ \\
\hline 0.222 & 0.936 & 0.284 & 0.394 & 0.586 & 0.302 \\
\hline
\end{tabular}

in acidic soil solutions, and strain rate plays a dominant role in affecting SCC behavior because of the effect of the dislocation movement. Increasing evidence confirms the effect of hydrogen on the SCC of pipeline steel in soil environments. As demonstrated in a previous study ${ }^{[6]}$, SCC may occur in soil environments; thus, investigation of the behavior and main effect factors of SCC in acidic soil in Southeast China is crucial. However, no report has focused on the effect of $\mathrm{pH}$ value on SCC in acidic soil environments to demonstrate clearly the relationship between SCC in acidic and near-neutral-pH media. Such a study would be very helpful in developing adoptive protection techniques for the SCC of pipelines in acidic soil areas.

This work aims to investigate the SCC behavior of X70 pipeline steel under various $\mathrm{pH}$ levels to obtain a detailed understanding of SCC mechanisms and predict SCC susceptibility within varying $\mathrm{pH}$ ranges.

\section{Experimental}

All samples in this work were made from a hotrolled X70 pipeline steel plate. The chemical composition and mechanical properties of the X70 pipeline steel are listed in Tables 1 and 2, respectively.

The microstructure of the as-received steel, which is composed of polygonal ferrite with small martensitic-austenitic particles distributed along the grain boundaries, is shown in Fig. 1.

The compositions of the simulated solution of acidic soil (named "red soil" in Southeast China) prepared in this work are shown in Table $3^{[6,13]}$. The $\mathrm{pH}$ value ranged from 3.5 to 6.5 according to the $\mathrm{pH}$ examination in the field; an acetic acid solution $(5 \%$ in mass) was introduced to change the $\mathrm{pH}$ values ${ }^{[13]}$.

Potentiodynamic polarization curves and electrochemical impedance spectroscopy (EIS) were employed to investigate the effect of the dynamic process of electrochemical reactions under varying $\mathrm{pH}$ values and their influence on the occurrence of SCC. Specimens were polished by using 800-grade emery paper and then coated with epoxy, thus leaving a working

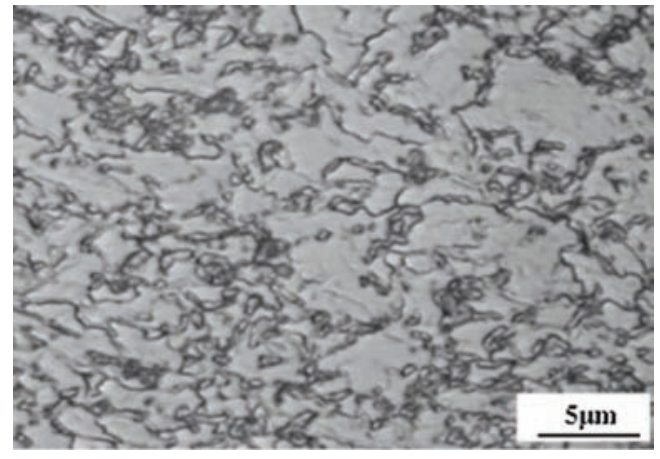

Fig. 1 Microstructure of the rolling plate

area of $1 \mathrm{~cm}^{2}$. All polarization curve measurements were conducted within a potential range from $-800 \mathrm{mV}$ to $1200 \mathrm{mV}$ against open-circuit potential (OCP). EIS were performed at both OCP and constant cathodic potentials. Prior to each test, the solution was de-aerated by using high-purity $\mathrm{N}_{2}$ gas for $2 \mathrm{~h}$, whereas the samples were pre-immersed for $0.5 \mathrm{~h}$. The administration of $\mathrm{N}_{2}$ gas was interrupted at the beginning to avoid the effect of solution disturbance.

Specimens for slow strain rate testing (SSRT) were created according to GB T15970.6 specification. The specimens were processed into flat samples with a working length of $25 \mathrm{~mm}$, width of $6 \mathrm{~mm}$, and thickness of $2 \mathrm{~mm}$. SSRT was performed with a strain rate of $0.5 \times 10^{-6} \mathrm{~s}^{-1}$ both in air and in solutions with various $\mathrm{pH}$ values under cathodic potential to investigate the relationship between SCC susceptibility and the $\mathrm{pH}$ values of the solutions. SSRT was conducted by using a WDML-30KN Materials Test System (Xi'an, China). Specimens were polished sequentially to 800 grade by using waterproof emery paper with the burnishing direction of the SSRT samples parallel to the tension direction. Prior to each SSRT in the solution, the specimen was immersed in the solution for $24 \mathrm{~h}$ without loading. Pure $\mathrm{N}_{2}$ gas was used during the whole test to remove dissolved oxygen.

A three-electrode system was used for both electrochemical tests and SSRT: X70 steel samples served 


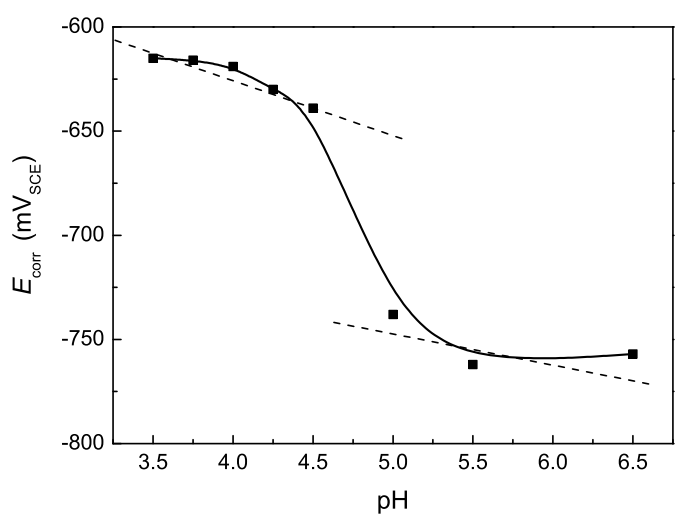

Fig. 2 Variation of OCP against $\mathrm{pH}$ value

as the working electrodes, a saturated calomel electrode was the reference electrode, and a Pt plate was the counter electrode. All tests were performed at ambient temperature (approximately $22{ }^{\circ} \mathrm{C}$ ).

\section{Results}

\subsection{Effect of pH Value on Electrochemical Reactions}

Fig. 2 shows the variation of OCP under different acidic-pH values. OCP decreases as the $\mathrm{pH}$ value of the solution increases from 3.5 to 6.5 . A sharp decrease in OCP is observed between $\mathrm{pH} 4.5$ and 5, which is approximately $100 \mathrm{mV}$; thus, the electrochemical reaction mechanism within this $\mathrm{pH}$ range changes greatly when the $\mathrm{pH}$ value shifts. This change results from the effect of $\mathrm{pH}$ value on reaction dynamics, which is discussed in detail in subsequent sections of the paper.

Fig. 3 shows the effect of $\mathrm{pH}$ value on EIS curves under various cathodic potentials. The shape of the curve is altered greatly when the potential shifts negatively from OCP to $-1200 \mathrm{mV}_{\mathrm{SCE}}$ or when the $\mathrm{pH}$ values increase from 3.5 to 6.5 . For all curves under cathodic potentials, two time constants can be observed. However, under different $\mathrm{pH}$ conditions, the curves indicate different electrochemical corrosion processes. Under $\mathrm{pH}$ of 3.5 and 4.5 (Fig. 3(a) and Fig. 3(b)), the high-frequency semicircle reflects the electrode reactions on the interface and electric double-layer processes at OCP; the secondary semicircle (i.e., the inductive loop) is related to the hydrogen evolution and absorption processes. Under cathodic potentials, such as -850 and $-1200 \mathrm{mV}_{\mathrm{SCE}}$, the high-frequency semicircle is related to the electric double-layer process or electrode reactions at the interface. The low-frequency part (the inclined line) is attributed to the diffusion processes of hydrogen evolution. By contrast, under $\mathrm{pH}$ of 5.5 to 6.5 (Fig. 3(c) and Fig. 3(d)), the high-frequency semicircle at OCP reflects the electrode reactions at the interface; the secondary semicircle is related to the resistance of the
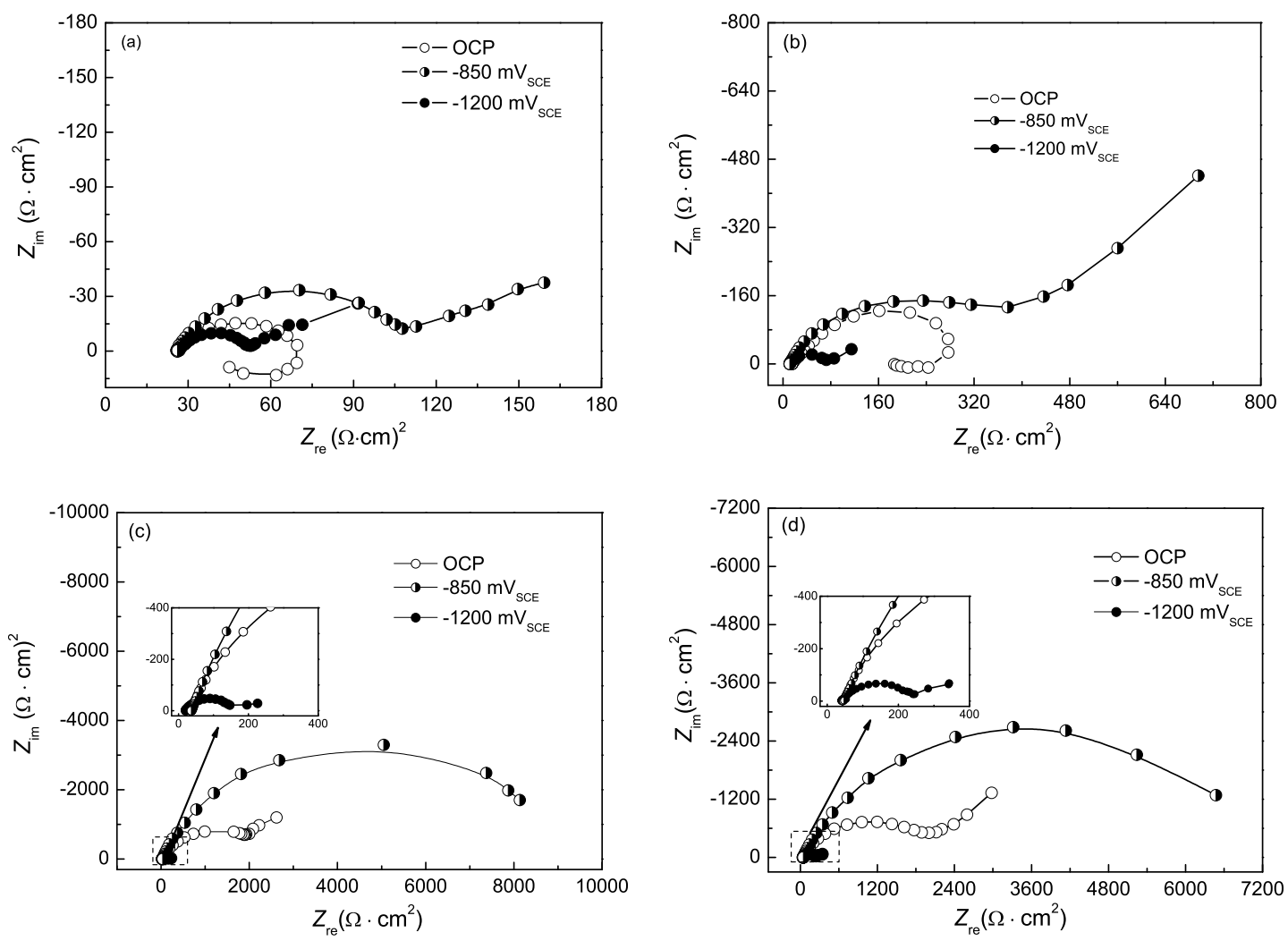

Fig. 3 EIS plots under various potentials in test solutions with pH of 3.5 (a), 4.5 (b), 5.5 (c) and 6.5 (d) 

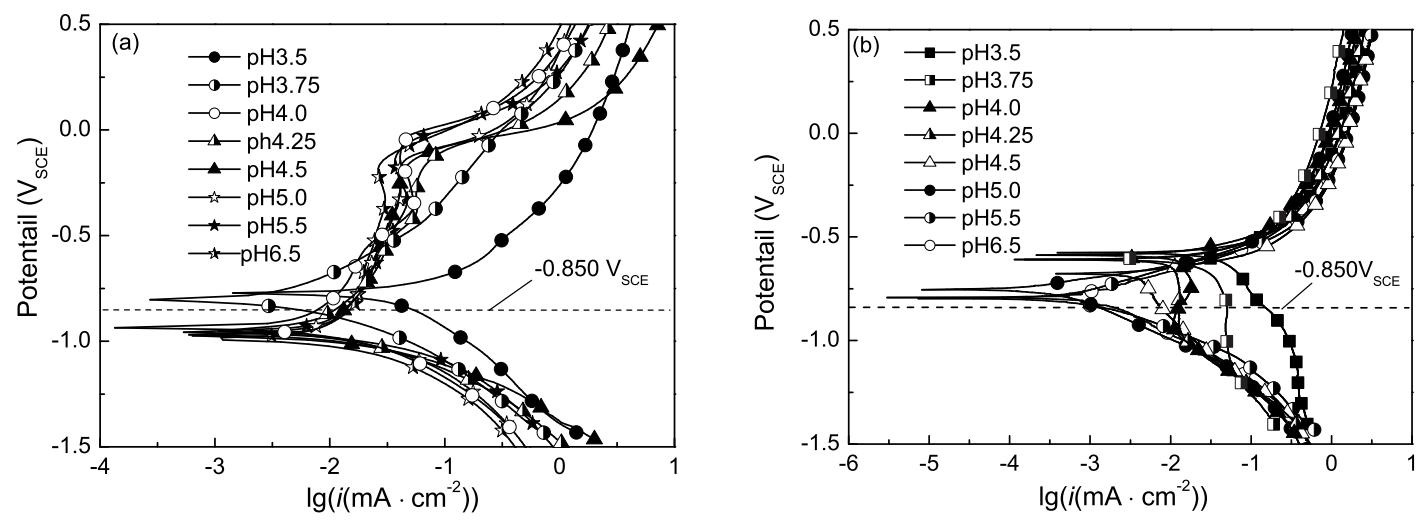

Fig. 4 Effect of $\mathrm{pH}$ values on electrochemical curves with scanning rate of 50 (a) and $0.5 \mathrm{mV} / \mathrm{s}$ (b)

corrosion product layer (i.e. Warburg impedence). When applied potential is conducted at $-850 \mathrm{mV}_{\mathrm{SCE}}$, only one semicircle can be observed with respect to the reduction of oxide layer as well as the hydrogen evolution. When the applied potential significantly negatively decreases (e.g., $-1200 \mathrm{mV}_{\mathrm{SCE}}$ ), the electrochemical processes are the same as that under lower $\mathrm{pH}$ conditions. The reason for this consistency is because some anodic reaction still exists within the localized area ${ }^{[17]}$ and some reactions of hydrogen evolution occur in other places ${ }^{[18]}$ within a weak cathodic potential range, such as from OCP to $-850 \mathrm{mV}_{\mathrm{SCE}}$.

In this case, the total charge transfer impedance $\left(Z_{\mathrm{tT}}\right)$ depends on the anodic impedance $\left(Z_{\mathrm{ta}}\right)$ and cathodic impedance $\left(Z_{\mathrm{tc}}\right)$. Thus, we obtain the following equation ${ }^{[19]}$ :

$$
\frac{1}{Z_{\mathrm{tT}}}=\frac{1-\theta}{Z_{\mathrm{ta}}}+\frac{\theta}{Z_{\mathrm{tc}}}
$$

where $\theta$ is the coverage of the cathodic reaction zone, which increases with decreasing cathodic potential. Under a weak cathodic range, the anodic effect cannot be neglected. However, $Z_{\mathrm{ta}}$ and $\theta$ increase and $Z_{\mathrm{tc}}$ decreases when the potential shifts negatively, thus making $\frac{1-\theta}{Z_{\mathrm{ta}}}$ decrease and $\frac{\theta}{Z_{\mathrm{tc}}}$ increase when applied potentials decrease negatively. $Z_{\mathrm{tT}}$ increases first if $\frac{\partial\left(\frac{1-\theta}{Z_{\mathrm{ta}}}\right)}{\partial E}>\frac{\partial\left|\left(\frac{\theta}{Z_{\mathrm{tc}}}\right)\right|}{\partial|E|}\left(\right.$ Eq. (1)). $Z_{\mathrm{tT}}$ reaches its maximum only if $\frac{\partial\left(\frac{1-\theta}{Z_{\mathrm{ta}}}\right)}{\partial E}=\frac{\partial\left|\left(\frac{\theta}{Z_{\mathrm{tc}}}\right)\right|}{\partial|E|}$. The anodic reactions are almost diminished when the potential decreases further; thus, $Z_{\mathrm{tT}}$ becomes closer to $Z_{\mathrm{tc}}$ and decreases along with the potential. Hydrogen evolution reaction dominates the electrochemical processes with the potential lower than $-850 \mathrm{mV}$ (Fig. 3). However, anodic reaction is present above the potential, particularly in solutions with higher $\mathrm{pH}$.

Fig. 4 shows the changes of the electrochemical polarization curves with shifting $\mathrm{pH}$ values. Fastscanning rate plots (Fig. 4(a)) reflect the electrochemical reaction at the crack-tip area, and the slowscanning rate curves exhibit the electrochemical characteristics at the non-crack-tip zone ${ }^{[20]}$. When $\mathrm{pH}$ is higher than 4, a small difference exists among fastscanning rate curves, and the zero current potential for each curve is approximately $-1000 \mathrm{mV}_{\mathrm{SCE}}$; thus, the electrochemical processes are the same in the crack tip, and the anodic reaction is dominant when the applied potential is above $-1000 \mathrm{mV}_{\mathrm{SCE}}$ (Fig. 4(a)). However, when $\mathrm{pH}$ is less than 4, the zero current potential of the fast-scanning rate curves shifts positively; thus, the reduction of $\mathrm{pH}$ intensifies the cathodic processes in the crack tip. For the non-crack-tip area, a change in $\mathrm{pH}$ primarily affects the cathodic processes but not the anodic reactions (Fig. 4(b)). The increase of the cathode currents when $\mathrm{pH}$ is less than 5 is related to the reduction of $\mathrm{H}_{2} \mathrm{CO}_{3}$ and $\mathrm{HCO}_{3}^{[6,15]}$; thus, OCP changes significantly at $\mathrm{pH}$ of approximately 4.5 when the $\mathrm{pH}$ value varies from 3.5 to 6.5 . The increase of the cathodic current with a $\mathrm{pH}$ of less than 5 is due to the intensification of hydrogen evolution, which can cause high concentrations of hydrogen to permeate into the bulk steel, thus leading to hydrogen-induced cracking or embrittlement.

To investigate the relationship between the $\mathrm{pH}$ value and SCC of the X70 pipeline steel, currents measured at the potential of $-850 \mathrm{mV}_{\mathrm{SCE}}$ by both fastand slow-scanning rate polarization curves are plotted in Fig. 5. The potential of $-850 \mathrm{mV}_{\mathrm{SCE}}$ is chosen because it is within the proper cathodic protection potential range for pipeline steels in soil environments. When $\mathrm{pH}$ is lower than 4 , the currents of the fast- and slow-scanning rate curves are both negative, indicating that both the crack-tip and non-crack-tip areas of the X70 pipeline steel are under the cathodic conditions during the occurrence of SCC (i.e., the mechanism for this case is $\mathrm{HE})^{[6]}$. Similarly, when $\mathrm{pH}$ is higher than 4 , the current of the fast-scanning rate curve at $-850 \mathrm{mV}_{\mathrm{SCE}}$ is positive and that of the slowscanning rate curve is negative; this result indicates that that the effect of $\mathrm{AD}$ at the crack tip and the effect of AD caused by hydrogen evolution and diffusion into the steel, as well as their synergistic effect, simultaneously propagate cracking (i.e., $-850 \mathrm{mV}_{\mathrm{SCE}}$ is located in the $\mathrm{AD}+\mathrm{HE}$ potential range). However, 


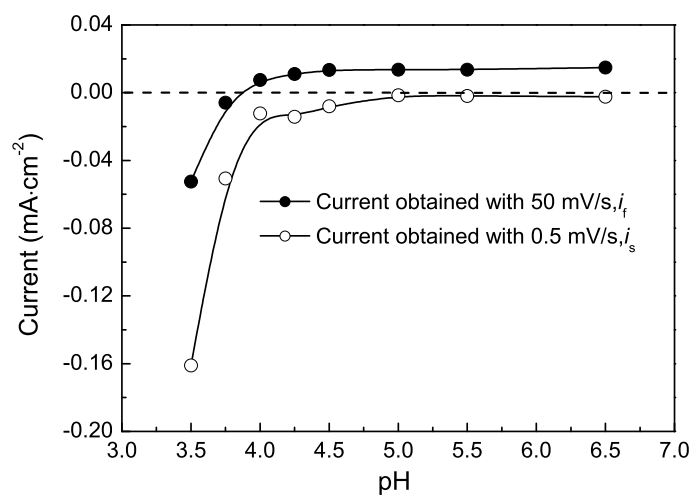

Fig. 5 Currents of slow-scanning rate curve $\left(i_{\mathrm{s}}\right)$ and fastscanning rate curve $\left(i_{\mathrm{f}}\right)$ obtained under varying $\mathrm{pH}$ values

when $\mathrm{pH}$ is more than 4.5 , the cathodic current, i.e., the current obtained with a slow-scanning rate, significantly decreases and close to zero at $\mathrm{pH} 5$ because of the inhibition of cathodic reactions ${ }^{[15]}$. This result is caused by the inhibition of the hydrolysis process of bicarbonate ions to carbonic acid and the formation of corrosion products as $\mathrm{pH}$ increases to more than 5 (Fig. 5). Thus, hydrogen evolution and diffusion into the metal matrix are significantly reduced, as well as the effect of AD and/or hydrogen-induced dissolution on SCC occurrence. Moreover, anodic reaction is dominant at the crack tip according to the current of the fast-scanning rate curves when the $\mathrm{pH}$ is more than 4 . When the $\mathrm{pH}$ is approximately 4.5, the anodic reaction rate at the crack tip and hydrogen evolution rate at the non-crack-tip zone show relatively high values. These results indicate that it is only when $\mathrm{AD}$ and $\mathrm{HE}$ are in good synergistic effects, i.e. there is enough high hydrogen charging current in non-crack-tip zone and high anodic current around the crack-tip, that SCC occurs in high susceptibility.

\subsection{Effect of $p H$ values on SCC occurrence in acidic soil solutions}

Fig. 6 shows the SSRT curves of X70 steel obtained under various $\mathrm{pH}$ at $-850 \mathrm{mV} \mathrm{SCE}_{\mathrm{SE}}$. A small difference exists among the tensile strengths of the material in the test media. The elongation obtained under $\mathrm{pH}$ of less than 4.5 is relatively lower than that examined in air. However, when $\mathrm{pH}$ is higher than 4.5, no clear difference exists among the elongations obtained in the solutions and in air.

To investigate the effect of $\mathrm{pH}$ variation on the SCC of X70 pipeline steel, the reduction-in-area loss ratio $\left(I_{\Psi}\right)$ and elongation loss ratio $\left(I_{\delta}\right)$ were calculated as the SCC susceptibility ratio. $I_{\Psi}$ and $I_{\delta}$ are defined as the following:

$$
I_{\Psi}=\left(1-\frac{\Psi_{\mathrm{pH}}}{\Psi_{0}}\right) \times 100 \%
$$

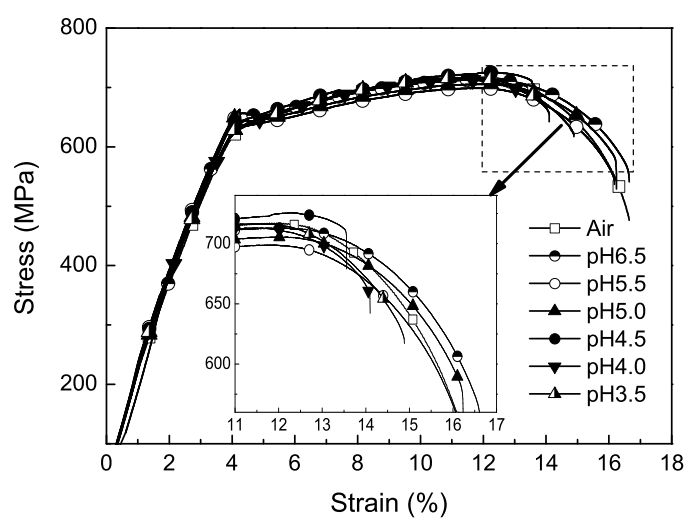

Fig. 6 SSRT curves of X70 pipeline steel under varying $\mathrm{pH}$ values

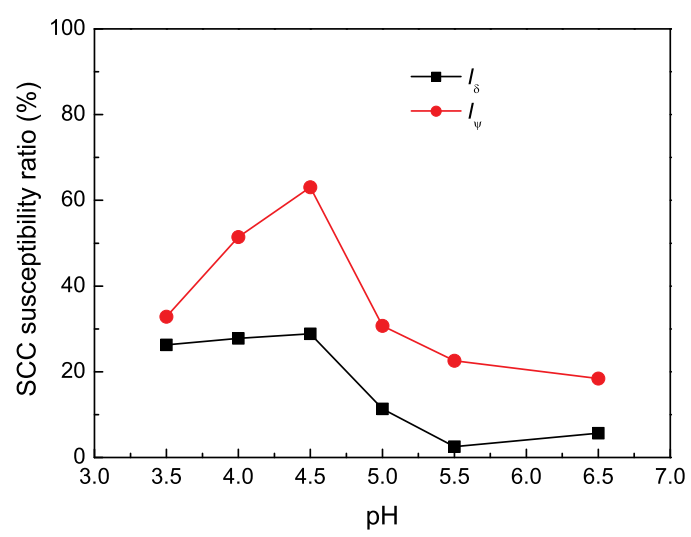

Fig. 7 SCC susceptibility ratio of X70 steel obtained under various $p H$ conditions

$$
I_{\delta}=\left(1-\frac{\delta_{\mathrm{pH}}}{\delta_{0}}\right) \times 100 \%
$$

where $\Psi_{0}$ and $\Psi_{\mathrm{pH}}$ are the reduction-in-area loss ratios measured in air and in solutions, respectively; $\delta_{0}$ and $\delta_{\mathrm{pH}}$ are the elongation loss ratios in air and in solutions with various $\mathrm{pH}$ values, respectively.

The calculation of $I_{\Psi}$ and $I_{\delta}$ is plotted in Fig. 7, which shows that $I_{\Psi}$ and $I_{\delta}$ follow the same trend. However, $I_{\Psi}$ is higher than $I_{\delta}$ under the same $\mathrm{pH}$ condition. Both variables have a maximum value near $\mathrm{pH} 4.5$, and either an increase or decrease in $\mathrm{pH}$ value leads to a reduction of SCC susceptibility. This reduction of $I_{\Psi}$ and $I_{\delta}$ under a $\mathrm{pH}$ value less than 4 is due to the HE mechanism (Fig. 5), which may also cause lower SCC susceptibility ${ }^{[21]}$. However, when the $\mathrm{pH}$ value is higher than 4.5, the reduction of SCC susceptibility is due to the decrease of the hydrogen charging current under the AD + HE mechanism; this finding also conforms the result in Fig. 5.

To investigate the evolution of SCC behavior with $\mathrm{pH}$ variations further, the fractographies of the samples after SSRT were observed by scanning electron microscopy (SEM) (Fig. 8). The results show a shift trend in brittle surface area distribution. Under $\mathrm{pH}$ 

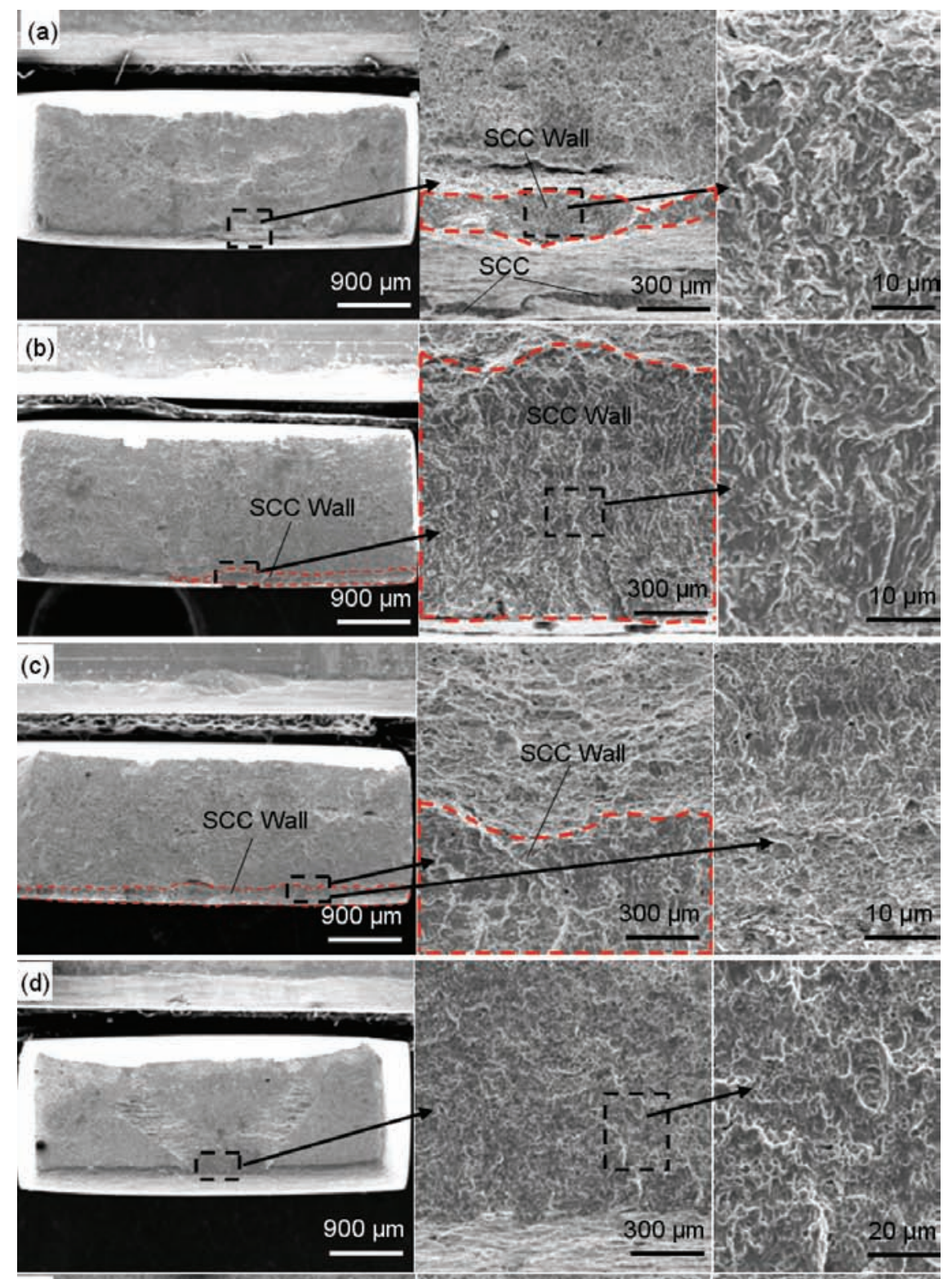

(e)
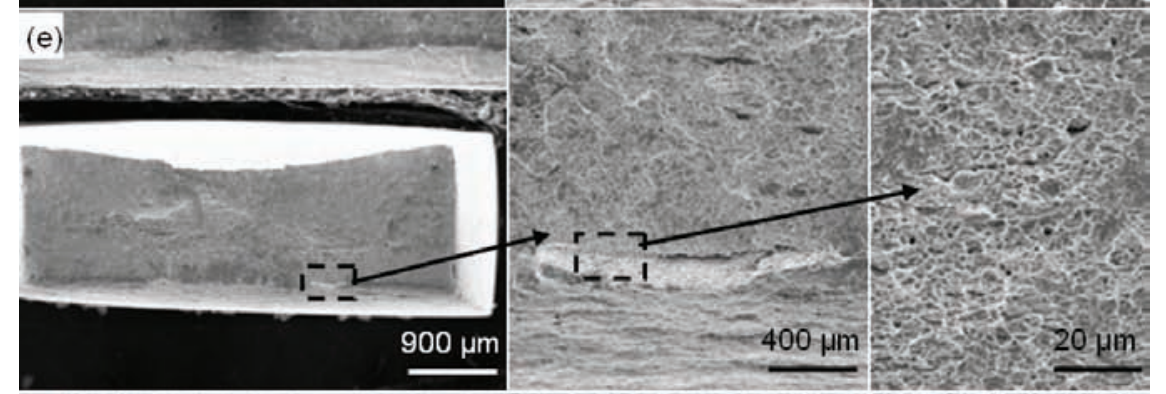

$$
\text { (n) }
$$

0

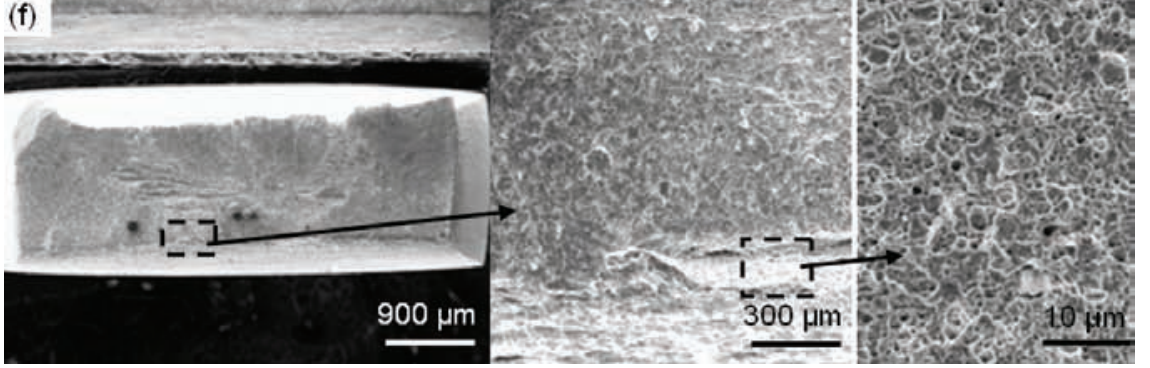

Fig. 8 Fractographies of X70 steel through SEM after SSRT in solutions with pH 3.5 (a), 4 (b), 4.5 (c), 5 (d), 5.5 (e) and 6.5 (f) 
3.5, a small area of brittle fracture surface exists on an edge of the fracture, and the rest of the area is covered with the dimples (Fig. 8(a)). When $\mathrm{pH}$ increases to 4 , a larger SCC zone can be observed (Fig. 8(b)). Under $\mathrm{pH} 4.5$, a considerably wider SCC-wall platform can be seen on the lower side of the fractography, as marked in Fig. 8(c) with a beautiful brittle pattern. Fig. 8(a) to Fig. 8(c) show the increase of SCC susceptibility by comparing the SCC-wall area; this finding is consistent with the SCC susceptibility ratio (Fig. 7) under $\mathrm{pH}$ 4.5. However, when $\mathrm{pH}$ is 5, 5.5, and 6.5 (Figs. 8(d) to Fig. 8(f)), all fracture surfaces exhibit dimple-fracture morphology, and no brittle fracture surface exists. Thus, if the HE effect (hydrogen charging current, shown in Fig. 5) is not strong enough, the considerable resistance to microSCC growth causes small SCC susceptibilities in these cases even though the effect of AD (anodic current, shown in Fig. 5) is large. This finding indicates that the effect of $\mathrm{AD}+\mathrm{HE}$ on $\mathrm{SCC}$ susceptibility requires the matching of these two effects.

\section{Discussion}

\subsection{Analysis of electrochemical Reactions of X70 steel in acidic soil environments}

In this study, the solution containing $\mathrm{HCO}_{3}^{-}$, $\mathrm{H}_{2} \mathrm{CO}_{3}$, and $\mathrm{H}^{+}$ions has a $\mathrm{pH}$ of less than 7 . The presence of $\mathrm{H}_{2} \mathrm{CO}_{3}$ is due to the hydrolysis of $\mathrm{HCO}_{3}^{-}$, and a lower $\mathrm{pH}$ corresponds to a higher $\mathrm{H}_{2} \mathrm{CO}_{3}$ distribution. $\mathrm{H}_{2} \mathrm{CO}_{3}$ is the highest-contributing species to the SCC of pipeline steels ${ }^{[15,22]}$. The primary cathodic reactions involving these species are as follows:

$$
\begin{gathered}
2 \mathrm{H}^{+}+2 \mathrm{e} \leftrightarrow \mathrm{H}_{2}, \\
2 \mathrm{H}_{2} \mathrm{CO}_{3}+2 \mathrm{e} \leftrightarrow 2 \mathrm{HCO}_{3}^{-}+\mathrm{H}_{2} \\
2 \mathrm{H}_{2} \mathrm{O}+2 \mathrm{e} \leftrightarrow \mathrm{H}_{2}+2 \mathrm{OH}^{-}
\end{gathered}
$$

However, some of these reactions are inhibited by the diffusion effect in an unsteady status. For the reactions defined in Eq. (4) and Eq. (5), the reductant diffusion from the bulk solution limits the reduction rate. Thus, if the scanning rate of the polarization curve is slow, such as $0.5 \mathrm{mV} / \mathrm{s}$ (Fig. 4(b)), the time between two potential steps to reach a quasiequilibrium reaction condition is much longer than that of the recovery time for the transmission of cathodic reactants. However, if the potential scanning rate is significantly increased, such as $50 \mathrm{mV} / \mathrm{s}$ (Fig. 4(a)), no reaction occurs between the reagents on the metal/solution interface. This effect inhibits cathodic reactions, thus resulting in the occurrence of anodic reactions at the crack tip under such a low potential (Fig. 4(a)). The anodic reactions of X70 steel in de-aerated low-pH solutions are expressed as follows ${ }^{[23]}$ :

$$
\mathrm{Fe} \rightarrow \mathrm{Fe}^{2+}+2 \mathrm{e}
$$

Mass diffusion plays a key role in affecting electrochemical reactions above approximately $-1000 \mathrm{mV}_{\mathrm{SCE}}$, thus inhibiting cathodic reactions under high potential scanning rates and promoting the occurrence of anodic reactions within the usual cathodic potential range (Fig. 4 and Fig. 5).

\subsection{Relationship between the property of SCC and electrochemical reactions of XY0 steel under vary- ing $p H$ conditions}

In the crack tip, the metal surface is covered without a polarizing layer or just with a half-baked electric double layer because of the continuous onset of fresh metal surfaces caused by SCC growth. When the newly generated metal surface is exposed to a solution under applied potentials, the electric double layer will be formed immediately and charged under the applied potential. For this case, the electrochemical processes can be simulated via electrochemical examinations by using a fresh-surface sample under non-equilibrium status. The $\mathrm{AD}$ can occur in a fresh metal at a far lower potential than the OCP obtained under nonequilibrium conditions (Fig. 4(a)) because the electrode surface remains quasi-fresh when polarized at $50 \mathrm{mV} / \mathrm{s}^{[20]}$. However, electrochemical reactions on a non-cracking surface occur in a quasi-equilibrium status, which can be simulated via electrochemical examinations by using a sample exposed in a solution under slow-scanning rate polarization (Fig. 4(b)). For this case, a sufficient cathodic reactant supply is available for hydrogen evolution reactions; as a result, diffusive hydrogen is introduced to the crack-tip area to increase the SCC growth rate caused by the synergistic effect of hydrogen on $\mathrm{HE}^{[24]}$ and/or hydrogen-induced dissolution $^{[4,25]}$. Thus, the SCC mechanism within the $\mathrm{pH}$ value range of 4 to 6.5 is $\mathrm{AD}+\mathrm{HE}$ (Fig. 5, Fig. 7 and Fig. 8). Moreover, SCC susceptibility under the HE mechanism is less than that under the AD + HE mechanism in some cases, such as SCC susceptibility ratios with $\mathrm{pH}$ values of 3.5 to 4.5 (Fig. 7), which result from the highest synergistic effect of AD and $\mathrm{HE}$ with a $\mathrm{pH}$ of 4.5. This result confirms that the $\mathrm{AD}$ effect can sharpen the crack tip to accelerate crack growth, and $\mathrm{HE}$ can both intensify the rate of $\mathrm{AD}$ at the crack tip and generate micro-cracks to help the main crack grow faster. AD and $\mathrm{HE}$ are able to accelerate the initiation and propagation of SCC; thus, SCC susceptibility decreases because of the weakening of the $\mathrm{AD}$ (in lower $\mathrm{pH}$ media) and $\mathrm{HE}$ effects (in higher $\mathrm{pH}$ solutions).

\section{Conclusions}

The $\mathrm{pH}$ value significantly affects SCC susceptibility and its electrochemical mechanism. The $\mathrm{pH}$ higher than 5 has no significant effect on electrochem- 
ical processes. However, when the $\mathrm{pH}$ is lower than 5 , the reduction in $\mathrm{pH}$ value intensifies the cathodic hydrogen evolution reactions, thus increasing the cathode current and corrosion potential. Under varying $\mathrm{pH}$ values, the SCC mechanism of X70 pipeline steel varies among $\mathrm{AD}, \mathrm{HE}$ and $\mathrm{AD}+\mathrm{HE}$. At $-850 \mathrm{mV}_{S C E}$, the SCC mechanism is $\mathrm{HE}$ if $\mathrm{pH}$ is less than 4 and is $\mathrm{AD}+\mathrm{HE}$ when $\mathrm{pH}$ is more than 4 . The $\mathrm{X} 70$ pipeline steel exhibits the highest SCC susceptibility under $\mathrm{pH}$ 4.5 because of the strongest synergistic effect of $\mathrm{AD}$ and HE. A weakening AD effect reduces SCC susceptibility when $\mathrm{pH}$ is lower than 4.5 , whereas a weakening $\mathrm{HE}$ effect reduces SCC susceptibility when $\mathrm{pH}$ is higher than 4.5 .

\section{Acknowledgements}

This work was financially supported by the National Natural Science Foundation of China (Nos. 50901041 and 51131001), the China Postdoctoral Science Foundation (No. 20100480196), and the Fundamental Research Funds for the Central Universities (No. FRF-TP-12-148A).

\section{REFERENCES}

[1] M.C. Li and Y.F. Cheng, Electrochim. Acta 52 (2007) 8111

[2] J.T. Bulger, B.T. Lu and J.L. Luo, J. Mater. Sci. 41 (2006) 5001.

[3] R.N. Parkins, W.K. Blanchard Jr and B.S. Delanty, Corrosion 50 (1994) 394.

[4] Y.F. Cheng and L. Niu, Electrochem. Commun. 9 (2007) 558.

[5] G. Van Boven, W. Chen and R. Rogge, Acta Mater. 55 (2007) 29.

[6] Z.Y. Liu, X.G. Li, C.W. Du, G.L. Zhai and Y.F.
Cheng, Corros. Sci. 50 (2008) 2251.

[7] Z.Y. Liu, G.L. Zhai, X.G. Li and C.W. Du, J. Univ. Sci. Technol. Beijing 15 (2008) 707.

[8] R.N. Parkins, Corrosion/2000, NACE, Houston, T.X., U.S., 2000, Paper No. 363.

[9] J.J. Park, S.I. Pyun, K.H. Na, S.M. Lee and Y.T. Kho, Corrosion 58 (2002) 329.

[10] W. Chen, F. King and E. Vokes, Corrosion 58 (2002) 267.

[11] J.A. Beavers and B.A. Harle, J. Off. Mech. Arc. Eng. 123 (2001) 147.

[12] Z.F. Wang and A. Atrens, Metall. Mater. Trans. A 27 (1996) 2686.

[13] Z.Y. Liu, X.G. Li, Y.R. Zhang, C.W. Du and G.L. Zhai, Acta Metall. Sin. (Engl. Lett.) 22 (2009) 58.

[14] Z.Y. Liu, X.G. Li, C.W. Du, L. Lu, Y.R. Zhang and Y.F. Cheng, Corros. Sci. 51 (2009) 895.

[15] Z.Y. Liu, X.G. Li, C.W. Du and Y.F. Cheng, Corros. Sci. 51 (2009) 2863.

[16] Z.Y. Liu, X.G. Li and Y.F. Cheng, J. Mater. Eng. Perform. 20 (2011) 1242.

[17] G.A. Zhang and Y.F. Cheng, Corros. Sci. 51 (2009) 1714.

[18] G.Z. Meng, C. Zhang and Y.F. Cheng, Corros. Sci. 50 (2008) 3116.

[19] Z.Y. Liu, X.G. Li and Y.F. Cheng, J. Mater. Eng. Perform. 20 (2011) 1242.

[20] R.N. Parkins, Corrosion 52 (1996) 363.

[21] Z.Y. Liu, G.L. Zhai, C.W. Du and X.G. Li, Acta Metall. Sin. 44 (2008) 209 (in Chinese).

[22] S. Nesic, J. Postlethwaite and S. Olsen, Corrosion 52 (1996) 280.

[23] A.Q. Fu, X. Tang and Y.F. Cheng, Corros. Sci. 51 (2009) 186.

[24] B. Gu, W.Z. Yu, J.L. Luo and X. Mao, Corrosion 55 (1999) 312.

[25] B. Gu, L.J. Luo and X.S. Mao, Corrosion 55 (1999) 96. 